\title{
Beginning of the Next Year or Continuation of the Last One? Analysis of Statistics and a Personal Opinion
}

\author{
Konstantin Korotkov* \\ University of St Petersburg, Russia
}

\section{Introduction}

In 2020, the entire world faced a formidable new danger: the coronavirus pandemic. Millions of people were infected and many died. Unprecedented measures were taken in all countries. The corona virus affects deep parts of the respiratory tract and lung alveoli. Like any virus, corona virus primarily affects people with a weakened immune system, taking certain drugs, and the elderly. The primary mortality from this virus in all countries was in older people. ${ }^{1}$ After 9 months of pandemic development, the course of the pandemic can be analysed, and it is important to do this for each individual country.

The new coronavirus SARS-CoV-2 is not the first coronavirus that mankind has encountered. The coronavirus became known back in the mid-1960s. In 2002, the SARS-CoV coronavirus caused an epidemic of severe acute respiratory syndrome (SARS). ${ }^{2}$ A total of 8437 cases were reported, of which 813 resulted in deaths $-9.6 \%$. Ten years later, another coronavirus, MERS-CoV, started raging, causing Middle East Respiratory Syndrome (MERS) with a $35 \%$ mortality rate!. ${ }^{3}$ Both of these viruses, as well as the new coronavirus, came to man from bats, who were unaffected. But unlike the avian influenza virus, coronaviruses are easily transmitted from person to person. Previous coronaviruses have been relatively quick to contain due to high mortality and relatively rapid development of symptoms. Oddly enough, the more lethal the virus is, the easier it can be localized. With new coronaviruses, infection is in most cases mild, allowing the virus to gain time and spread further.

With viral infections, the host organism triggers various protection mechanisms. In addition to the production of antibodies, it starts a program of cell apoptosis, interferon production, and a number of other mechanisms. In order to survive in the host or ganism, viruses resort to three main strategies: "secret presence" allows the virus to avoid immediate recognition by the immune system; "sabotage" leads to damage to the protective mechanisms of the immune system; "exploitation" is aimed at using the immune system for its own purposes. Some of the molecular mechanisms through which viruses implement each of these strategies are currently described. The information obtained by scientists allowed the head of the international group of scientists' biologist Trevor Bedford to assume that the transition of the SARS-CoV-2 virus from a bat to an intermediate host occurred 20-70 years ago. ${ }^{4}$

He explained that all changes occurring with the virus fit into the logic of natural evolution common to viruses. In so doing, the scientist refuted theories about genetically engineered virus creation. There's another point of view. The virus was originally created in the American laboratory of the University of North Carolina, an article about it was published in the most prestigious scientific journal Nature in 2015. Realizing what this can mean, the U.S. government hastened to adopt a moratorium on experiments on human pathogens.

The research was transferred to the Institute of Virology of the Chinese Academy of Sciences in the city of Wuhan, well; one of the active participants in research in America was Chinese Shi Zeng-Li. But then the Chinese couldn't keep track of the test tubes or the staff, and the virus went out to walk outside the laboratory walls. Let's not claim that it was, but this scenario is quite possible in today's world. The coronavirus affects deep parts of the respiratory tract and lung alveoli. ${ }^{5}$ Thus, the pathology is similar to SARS, but the fibrosis and thickening of the lungs is not that serious. However, if the disease is serious, the patient should be connected to a ventilator for a few days. In most cases, this allows all activities to be

\begin{tabular}{|l|l|}
\hline Quick Response Code: & *Corresponding author: Konstantin Korotkov, University of St Petersburg, Russia \\
Received: 11 January, 2021 & Published: 09 February, 2021 \\
& Citation: Konstantin Korotkov. Beginning of the Next Year or Continuation of the Last One? \\
Analysis of Statistics and a Personal Opinion. Glob Scient Res Env Sci. 2021;1(2):1-3. DOI: \\
$10.53902 / G S R E S .2021 .01 .000506$
\end{tabular}


carried out successfully and the person returns to normal life after treatment. Like any virus, coronavirus primarily affects people with a weakened immune system, taking certain drugs, and the elderly. The main mortality from this virus in all countries is in elderly people.6 If you maintain your health, your immune status, you have every chance to survive safely and this becomes just another invasion.

\section{Analysis of COVID-19 Situation in Russia in 2020}

The situation with COVID-19 in Russia in 2020 was much better than in many other countries. To understand the reason for this difference will be the goal of further analysis for world science. Total by the beginning of 2021, we had 3,402,000 reported cases with 61,837 cases of deaths that is $1.81 \%$. It is clear that these statistics are quite approximate: not all the people have been documenting their disease, having treatment at home without passing later tests, so in reality; this percentage would be even smaller. At the same time, statistics of deaths we may consider quite precise, as all the cases of corona virus deaths were quite well documented. Statistics of deaths from corona virus in different age groups confirms the standard view that the most vulnerable are the oldest. Statistics of deaths from corona virus in different age groups confirms the standard view that the most vulnerable are the oldest. For all age groups, the concomitant disease is shown to be an additional risk factor. Obviously, the weaker a person's immune system, the more susceptible they are to viruses. In children less than nine years old, it was practically no cases of corona virus. Simultaneously, we do not see a big difference in mortality between men and women.

Public transport was operating in Russia continuously without interruption. Still, the number of people using it was less than usual, as many people stayed at home using an online activity. Since July, theatres, stores, and restaurants have been opened in Russia, and now everything is fully functional, but up to 23 hours. The halls are filled to no more than $50 \%$, in all public places, people must wear masks, and in many places, they measure the temperature at the entrance. People without restrictions travel around Russia, and since August, all popular recreation areas are filled. From August, thousands of people have been flying to Turkey, where most of the hotels and restaurants were opened. One could have expected a sharp spike in morbidity since July, but as can be seen from Figure 1 , it did not happen. The October surge is connected with the usual seasonal peak of morbidity.

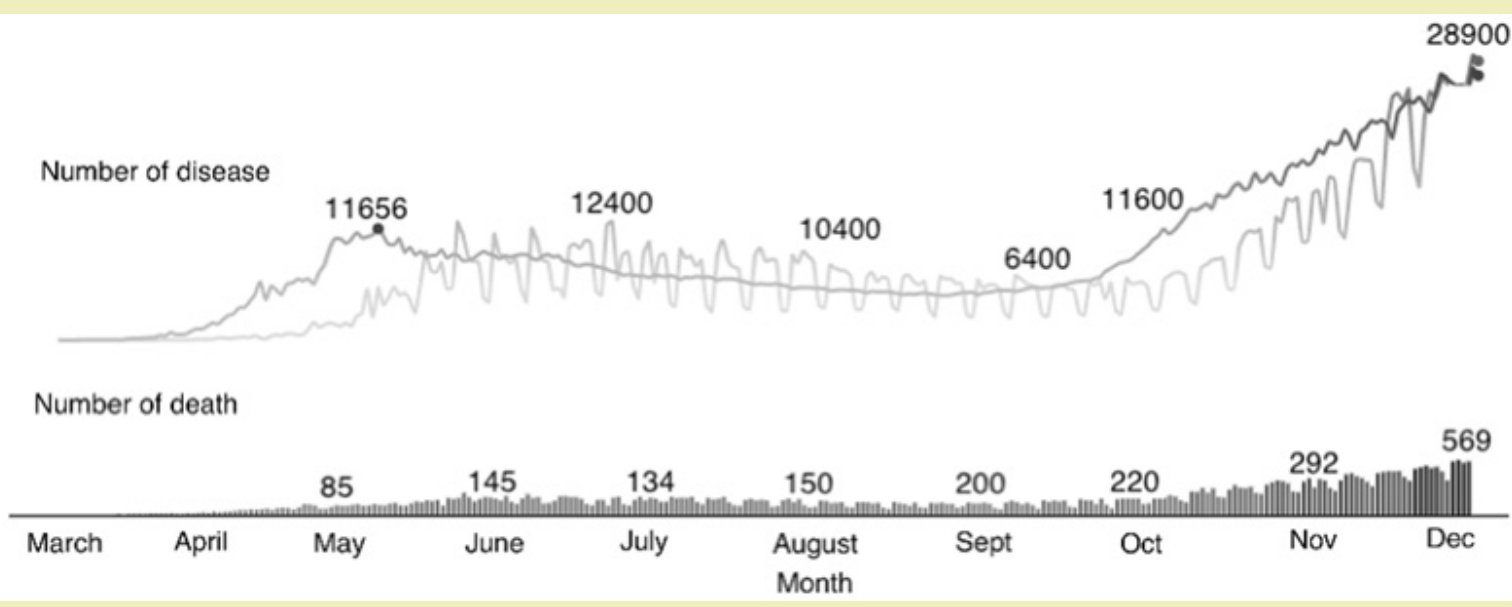

Figure 1: Distribution of diseased people and the number of deaths in Russia in 2020.7

\section{Discussion}

Undoubtedly, the corona virus is very contagious; it is dangerous for people with reduced immunity, the elderly, and people with chronic diseases. Therefore, wearing masks in public places is a reasonable measure. All of us should be careful, wash our hands, if you get sick - stay at home and be treated. We have great respect for the doctors, who selflessly fight this contagion, and we extend our condolences to those who lost their relatives and friends. But after many months of pandemic development, it is evident that restrictive measures do not contribute much to its elimination, and the economic and psychological damage is obvious. Maybe it's time to get back to everyday life? And can we assess the impact of the whole situation with the suspension of thousands of businesses, shops, restaurants, theatres, and airlines on the country's economy and the population's living standards? Hundreds of thousands of people were unemployed; many businesses went bankrupt. ${ }^{7}$ Millions of unemployed were thrown out on the street, not because they were such evil capitalists, but because the government put them in such conditions. The tourist business, which did not bring millions anyway, collapsed, and the most active season, summer, was zero.

So, shouldn't we have thought about it before the general quarantine was declared? How natural was it to stop the whole social life and condemn people to isolation? And can we assess the impact of the whole situation with the suspension of thousands of businesses, shops, restaurants, theatres and airlines on the economy of the country and the living standards of the population? Politicians involuntarily become psycho-bioterrorists. Panicking, they cause a fall in immunity, resulting in the rise of infectious diseases, alcohol abuse. Crime has increased by 30-40 percent across Moscow. That's what politicians, who think they understand everything do. Alas, the world has absorbed the panic attack, depriving the ability to reasonably assess what is happening. Anti-plague measures in 
the cemetery are as much needed as a year's supply of toilet paper. The virus outside the human body dies in a couple of hours. Everybody's rooftops are gone.

\section{Conclusion}

First of all, we need to know that the flash is still on. You have to be careful, wash your hands, do not gather in large numbers, if you get sick and stay at home. You have to go out in the sun. Under the influence of sunlight, the virus will disappear in a few minutes. And ultraviolet rays help to produce vitamin $\mathrm{D}$, which stimulates immunity. Don't panic. Even if you get sick, it's okay, the as we can see, the situation with this pandemic is very complicated, and there are no unequivocal solutions to deal with this situation. It will take a long time to analyze the situation and plan further actions.

\section{Acknowledgments}

None.

\section{Funding}

None.

\section{Conflicts of interest}

Author declares that there is no conflict of interest.

\section{References}

1. Great Combinator WHO. Summary of probable SARS cases with onset of illness from 1 November 2002 to 31 July 2003. 2015.

2. WHO. Middle East respiratory syndrome coronavirus (MERS-CoV).

3. Maciej F Boni, Philippe Lemey, Xiaowei Jiang, et al. Evolutionary origins of the SARS-CoV-2 sarbecovirus lineage responsible for the COVID-19 pandemic. Nature Microbiology. 2020;5:1408-1417.

4. Chilvers MA, McKean M, Rutman A, et al. The effects of coronavirus on human nasal ciliated respiratory epithelium. European Respiratory Journal. 2001;18:965-970.

5. https://nplus1.ru/material/2020/03/18/virus-evolution

6. https://ourworldindata.org/coronavirus

7. https://tradingeconomics.com/united-states/unemployed-persons

8. https://www.nytimes.com/2020/04/09/business/economy/ unemployment-claim-numbers-coronavirus.html 